\title{
Remixing Selfies: Arts-based Explorations of Funds of Knowledge, Meaning-Making, and Intercultural Learning in Literacy
}

\author{
Kinga Varga-Dobai \\ Georgia Gwinnett College \\ U.S. A.
}

\begin{abstract}
This article describes an arts-based writing project, the Cultural Selfie, used in a pre-service teacher education classroom to explore the concept of funds of knowledge and to develop intercultural awareness. The Cultural Selfie as a visual interpretation provided a space for pre-service teachers to reflect critically on their everyday cultural and literacy practices and their teacher Self. In doing so, they used literacy as a form of meaningmaking to examine concepts such as privilege, cultural bias, and discomfort, as well as strength and weakness in relating to different cultures.
\end{abstract}

KEYWORDS: funds of knowledge, intercultural learning, remix, meaningmaking, Selfies

Context

Remixing Arts, Self, and Intercultural Learning

Cultural Selfies, a Funds of Knowledge Project

Exploring Funds of Knowledge

Interpretation

Discussion

Implications

References

Author Contact

Anna stands in front of the classroom as she is walking us through her Cultural Selfie slideshow, an arts-based and multimodal writing assignment that explores the cultural and literacy identity of pre-service teachers. Anna is a senior in our teacher training program, and she is one of the many pre-service teachers who are first-generation US-born immigrants with rich intercultural experiences and backgrounds. Anna's parents immigrated to the United States before Anna was born. She is the oldest child and the first one in her family to attend college. Anna describes herself as the translator of her family, who has been "speaking for" her parents since kindergarten. Just recently she had to submit her brother's college application because Anna's job, as she described it, was to take care of all the family's "official business" and paperwork. In her family Anna is respected because she speaks in impeccable English, and she has a calm confidence about her that makes everyone listen to her. Anna's favorite object that she captured in a visual image and shared with us as part of her Cultural Selfie was her high school Honor's Medal and a picture of her parents. She is overcome with emotions when 
she mentions her father who did not get past his $4^{\text {th }}$ grade education and who has worked three jobs for the last 20 years to support his children. Working hard and helping others, she claims, are the funds of knowledge that she learned in her family.

\section{Context}

The concept of funds of knowledge was coined by Moll, Amanti, Neff, and Gonzalez (1992) and described as the "historically accumulated and culturally developed bodies of knowledge and skills essential for household or individual functioning and well-being" (p. 133). Understanding this concept is an essential part of culturally responsive instruction (Ladson-Billings, 2006; Nieto, 2010). Every student comes to school with a certain amount of knowledge that they have learned just by being part of a family and community. Anna's funds of knowledge are evident in her language skills as an interpreter and in her ability to show care for others-helping each other is what kept her family together. Kiyama (2014) describes these types of kinship networks and exchange relations as "culture glue" (p. 25). Various language practices-for example, storytelling, role play, or social practices (Street, 1995; Mui \& Anderson, 2008) such as shared child care and celebrations of important holidays - could also be considered aspects of funds of knowledge that are practiced in the family or community and that children learn and carry through life. Anna's funds of knowledge also extend into what Hogg (2011) described as "knowledge from experiences such as schooling, peers and popular culture" as well (p. 670). Anna's ability to navigate college-related procedures, such as registering for classes or taking exams, is perceived as a form of knowledge in her family that allows her to guide her relatives. In her Cultural Selfie, Anna also touches upon what Zipin (2009) and Wiltse (2014), as well as Marshall and Toohey (2010), have described as the dark or difficult aspects of funds of knowledge, such as Othering and the experiences of cultural bias. Because she was often Othered as the "little Hispanic girl whose parents did not speak English," she has developed her own judgment towards people who look different from her. For example, she always thought that "White ladies cannot cook" until she became close friends with Erica, one of her colleagues, who showed her "what great Southern food tastes like," as Anna described it.

I am an associate professor of language and literacy education in a teacher training program in the southeastern part of the United States, where I work with pre-service teachers in their senior year. Because of my personal background as an immigrant whose first language is not English, the exploration of the concept of funds of knowledge became central for my course, "Language, Literacy, and Culture." This course focuses on the literacy education of culturally and linguistically diverse students, the social and cultural theories of language acquisition, and literacy as a meaning-making process. Additionally, Language, Literacy, and Culture is also used as a platform to engage with intercultural learning practices. The framework of interculturalism used in the course targets 
competencies in three major categories: intercultural awareness (with focus on developing knowledge of the Self in relation to other cultures), intercultural collaboration and communication (with focus on students' abilities to communicate effectively with people from diverse cultural backgrounds), and application and problem solving (with focus on students' abilities to apply intercultural knowledge to global challenges).

I firmly believe that for pre-service teachers these competencies are necessary because the school settings where they will work are dominated by racial, economic and linguistic diversity. For those who come from communities with little racial or cultural diversity, the highly diverse schools represent a challenge, and some of these pre-service teachers frequently experience discomfort and uncertainty in their interactions, especially in the face of linguistic diversity. These pre-service teachers understand that teaching is more than simply developing skill-sets or delivering content and that creating relationships with students is necessary to understand who those students are-both academically and culturally. Knowing how to become comfortable with diversity, how to engage students in spite of the language differences, or how to become advocates for students requires that pre-service teachers examine their funds of knowledge, their dispositions and understanding of the impact of culture on learning and literacy. This form of "consciousness raising and identity work, "takes time" as Pirbhai-Illich claimed (2010, p. 262). The more essential part of culturally responsive instruction and culturally sustaining pedagogy (Paris \& Alim, 2017) calls for teaching practices that recognize and sustain the importance of cultural ways of being as a source of knowledge. Thus, teachers need to become researchers who investigate, ask questions, get to know the families, and listen to the stories children tell. To become familiar with this type of work, pre-service teachers in this project first engaged with their own self-discovery.

In this manuscript I discuss the theoretical underpinnings that informed a class project, the Cultural Selfie, designed for pre-service teachers. Specifically, I describe how the focus on intercultural awareness prompted me to explore the concept of funds of knowledge (Meoli, 2001; Moll et al., 1992; Kiyama, 2014; Zipin, 2009) in literacy teaching and learning. I discuss how the framework of remixing (Gainer \& Lapp, 2010; Knobel \& Lankshear, 2008) and of literacy as a form of meaning-making (Harste, 2003) allowed for an arts-based (Chilton, 2013; Leavy, 2015) exploration of each student's cultural, literacy, and teacher Self. I share examples to demonstrate how this arts-based approach allowed pre-service teachers to engage with meaning-making and how the Cultural Selfie project contributed to their intercultural learning (Bennett, 1996).

\section{Remixing Art, Self, and Intercultural Learning}

My research interest on intercultural learning was influenced by Bennett (1986) and Rizvi (2009), who believed that intercultural competence always begins with the understanding of the Self. My own personal and academic journey taught 
me that, in the process of becoming a member of a different culture, learning about the Self was crucial and inevitable. I learned that my perceptions of the new cultures and people that I came in touch with were always shaped by my own cultural beliefs with which I grew up. From a professional perspective, as an academic developing a research interest in literacy I found myself tapping into my own socio-cultural experiences as a user of various languages and literacy practices. In this process, the power of art (drama, creative writing, and photography) helped me in generating knowledge about myself as a cultural being and my situatedness as a researcher, and I hoped that pre-service teachers could also use this power of artistic experience to create their Cultural Selfies. The Cultural Selfie, as a form of self-portrait, relies on the remixing of various creative forms of expression-for example, drawings, photography, object narratives, and poetry-to explore the meaning and relevance of one's Cultural Self. To remix means, according to Knobel and Lankshear (2008), "to take cultural artifacts and combine and manipulate them into new kind of creative blends" (p. 22). Similarly, Gainer and Lapp (2010) describe remix as a form of writing and comprehendinga textual transaction between the person and the artifacts of the outside world. To that end, and in order to draw on textual understanding (Rose, 1994) to construct new meaning and explore funds of knowledge, my students used remix as a form of meaning making and extended learning to the home and community.

Remix as a form of digital storytelling and of the meaning-making process helped these pre-service teachers, as Becker (2014) described, move away from viewing literacy as "a discrete set of text-based skills to the understanding that literacy is culturally and socially shaped" (p. 20). Chilton (2013), as well as Fraser and Sayah (2011), further argued that creative forms of expression, in fact, go beyond generating knowledge about a phenomenon; they also elicit change and transformation in life. In this creative "meaning-making process" (Kalantzis, Cope, Chan, \& Dalley-Trim, 2016; Kress, 1997; Kress \& Van Leeuwen, 1996; Wajskop \& Peterson, 2015), we relied on the concept of Selfie (Goffman, 1959; Katz \& Crocker, 2015; Koliska \& Roberts, 2015; Nemer \& Freeman, 2015; Saltz, 2014) because of its appeal as a popular culture activity. Selfies as a new visual genre and form of self-portrait (Saltz, 2014) focus on the presentation of Self (Goffman, 1959). Selfies are a form of visual communication (Katz \& Crocker, 2015), both depiction and explanation of thoughts (Nemer \& Freeman, 2015). Selfies assert control over the embodied Self (Tiidenberg, 2014). Koliska and Roberts (2015) describe Selfies as a "visual representation of one's Self and a photographic representation and formation of identity" (p. 1672) performed for a particular audience. This performance of the Self was useful for our project on funds of knowledge because the visual nature of the genre allowed pre-service teachers to create impressions about the Self in relation to the social space where the Selfie was taken (Koliska \& Roberts, 2015), such as their community. Selfies also allowed for the manipulation of those impressions. Koliska and Roberts (2015) called this form of meaning-making a "visual interaction" (p. 1672) between the person and his or her environment, and a kind of social role presentation where the attention is not only on the individual but the surrounding social and physical space. The Selfie as a "public performance of witnessing" (Koliska \& Roberts, 
2015 , p. 1676) provided opportunities to pre-service teachers for real-life connections that, according to Ladson-Billings (2006), expand definitions of literacy to knowledge rooted in lived experience.

\section{Cultural Selfies, a Funds of Knowledge Project}

Through photography, poetry, and object narratives, this remixing project allowed for the creation of an arts-based self-portrait, the Cultural Selfie, which I used as data for my analysis. Pre-service teachers enrolled in the Language, Literacy, and Culture course during Spring semester 2016 submitted this class assignment. This class included 17 female pre-service teachers who self-identified as European American, African American, Korean American, and Mexican American. For this study I received IRB approval, and consent forms have been signed by all pre-service teachers. It was communicated that their consent was voluntary and that they could withdraw their consent anytime. For the purpose of this manuscript I looked closely at student work that reflected or addressed the process of meaning-making, and thus I obtained data used in this manuscript from the Cultural Selfies of eight pre-service teachers. Data were also derived from the whole group discussions and informal conversations that occurred and were recorded during our class time as pre-service teachers presented their Cultural selfies. These discussions and informal conversations were transcribed after the semester ended, and data has been stored on a password-protected computer. Following the IRB protocol to ensure confidentiality, the names of the pre-service teachers have been replaced with pseudonyms.

In preparation for this project, and in order to become familiar with the concepts of funds of knowledge and literacy as meaning-making, pre-service teachers read academic articles throughout the semester on these concepts, and they discussed these articles in literature circle groups in class. The Cultural Selfie assignment consisted of three major parts: Self-data collection, reflection, and analysis. Pre-service teachers collected information about their own life, investigating the four major categories of their identity:

- Self as part of Family

- Self as part of Community

- Self as Literacy Person

- Self as Teacher

In order to help pre-service teachers think more deeply about their identities, I broke these categories down further to 12 aspects. Thus, while they were investigating their Self as part of their Family, I asked that they explore specific aspects such as their name, their favorite characteristic, and an important object. In terms of Community as part of their identity, they examined their privilege, cultural bias, and their cultural value. Their Literacy Self entailed literacy practices of everyday life, their favorite literacy practice, and a favorite book. Finally, Teacher Self included their strength and weakness in teaching culturally diverse students, an "I am" poem, and an actual selfie. We discussed in detail how these elements, 
for example an important object, carry information about a person and their family history, or how the examination of privilege positions an individual within their community shaped by cultural, racial, economic or gender relations. For each of these aspects of their Self, I provided prompting questions such as:

What is your privilege: your skin color, your economic status, the location where you grew up, your home?

I then asked students to design meaningful visual interpretations of these 12 aspects in the form of photographs and to attach a narrative to each of those photographs. In these narratives they explained their artistic choices and meaningmaking process and how that visual interpretation translated a particular aspect of their Self. As I had designed the Cultural Selfie to be a digital project, I requested that pre-service teachers use a collaborative software called Padlet that allowed them to create a slideshow with their photographs and their narratives. Finally, the last section of their Cultural Selfie included an essay on what they learned about themselves and their funds of knowledge in the course of the project.

By creating visual interpretations of the various aspects of their Self, the Cultural Selfie extended analytical thinking. In this process of "active meaningmaking" (Gainer \& Lapp, 2010, p. 58), pre-service teachers brought together personal, familial, cultural, and academic components, utilizing various artifacts and resources of everyday life to construct new knowledge about themselves. Selfies allowed them to objectify the different concepts that are part of their lives such as bias or prejudice, in order to witness what is often invisible or unspoken. Each slide in the Cultural Selfie, thus, included a story through which pre-service teachers offered interpretations of their identity.

\section{Exploring Funds of Knowledge}

I used thematic analysis described by Riessman (2008) as a methodological approach that relies on the narrative (story) as primary source of data and meaning-making unit. In this process, I paid attention to both thematic and structural aspects of the visual narratives, specifically how preservice teachers remixed elements of their life to design their photographs and what they said about their interpretations and the meaning-making process. As language, whether written, oral, or visual, is ambiguous and its interpretation is mediated by the theoretical perspective of the investigator, I do not claim that my analysis provides an "unalloyed subjective truth" (Riessman, 2005, p. 6) about the cultural, literacy, and teacher Self of these pre-service teachers. The analysis rather focuses on how these pre-service teachers articulated meaning through literacy and how they practiced self-reflection in the process. Because of my interest in meaning-making and funds of knowledge, for the purpose of this manuscript, as I noted above, I looked closely at student work that reflected or addressed the process of meaningmaking. I further narrowed down the sample based on what I identified as similarities in their meaning-making and, within limits of manageability, I included some examples. Equally noteworthy stories that did not explicitly reflect on 
meaning-making have not been considered in my sample.

\section{Interpretation}

While investigating the various aspects of their Self, pre-service teachers often relied on forms of meaning-making that involved the space of the home, feeling of textures, or the body (facial expressions, clothing, and jewelry) as well as written artifacts (letters and notes). In their discussion of multimodal literacies and meaning-making, Kalantzis et al. (2016) claim that besides language and image, human beings can also make meaning through spatial, tactile, and gestural modalities. Buildings, landscapes, and ecosystems that people inhabit or come in contact with will produce relationships and carry patterns of meaning through which people navigate their life. In putting together their Cultural Selfie, pre-service teachers relied on these spatial, tactile, and gestural meanings as well as on writing as a form of meaning-making, and they used image (usually photographs) to offer visuals of those interpretations.

\section{Spatial Meaning}

In visually representing Cultural Bias, Nina turned towards her childhood home and took a picture of their family house in the Blue Ridge Mountains (see Figure 1). The outside wall covered with decorative objects and the hand-made art scattered around the yard represented members of her own family who did not have the formal education and well-paying jobs required to afford a home in the suburbs. According to Nina, her home made her aware of the economic gap between her family and middle-class America. Her bias, as Nina described it, was that she also thought "people who live in the mountains were not very smart." Taking a picture of the front of their house and the space around it allowed her to reflect on her own bias. What she considered "trashy and low-class" as a young woman became a representation of the inventiveness of her family members who created a home that looked artistic and unique. For example, her father used hubcaps to cover the front of the house, and the arrangement of those objects created a visual resembling of folk art. "I now realize that the people I know are smart and skillful in art, in manual labor, only they do not have a formal education." She also realized that, in fact, she retained many of those artistic qualities as her funds of knowledge. For example, the picture frame she had recently turned into a necklace holder reflected that family trait of repurposing artistically.

Similarly to Nina, Kate also used the space of her childhood and one object from her family house, a Pink Panther plush toy, to describe herself as part of her family. According to Kate, by "being smart, clever, funny, likable, out of the box, comfortable in his pink skin," the Pink Panther represents her own life-skill and funds of knowledge that she inherited from the home where she grew up. Another pre-service teacher, Linne, a first generation immigrant, used a photograph from 
her childhood home to define privilege as part of her funds of knowledge. The photograph became a symbol of her privilege that motivated her to study and become the first college graduate in her family. On the black-and-white photograph, a shy, 6-year old Linne is pictured holding a small blackboard with her name and a number written on it in chalk upon her family's entry to the United States.

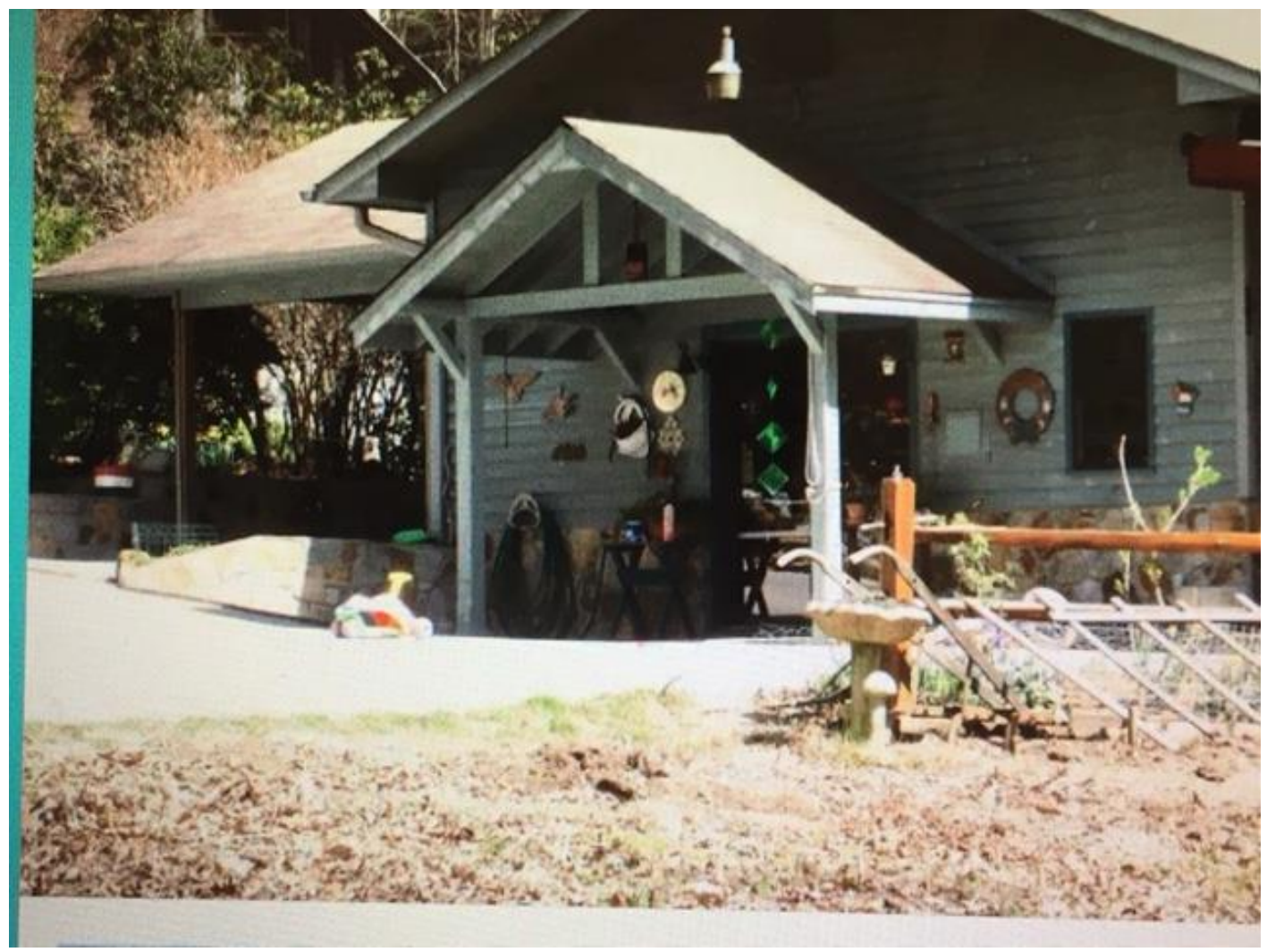

Figure 1. Family Home

\section{Gestural Meaning}

Gestural meanings are made through physical appearances, movements, facial expressions, or gaze (Kalantzis et al., 2016). The term also refers to the various ways in which we present our bodies through clothing, jewelry, or body modifications as forms of presentation of the Self. In the process of describing aspects of their Self and their funds of knowledge, several pre-service teachers reflected on the relevance of physical gestures and their use of them as a form of self-presentation or as a source of observation to learn about others. Etta, a parttime photographer, described her teacher Self in relation to her ability to observe, watch, and notice to capture simple but special moments in people's lives. The 
picture of her own camera represented this ability: to sit back and be an observer of people around her. Etta shared:

The way people laugh or use their hands when they communicate tells a lot about who they are. That's why I like to spend a little time with my clients before the photo-shoot, so I can get a sense of who they are, and how I could make them feel more comfortable in front of the camera.

Photography taught her patience to look for physical expressions and gestures that embody details about a person beyond what is immediately visible. She hoped that this ability would contribute to her success as a teacher.

Similarly, Ann used the gestural meaning of bodily appearance as she described her ladybug tattoo, a representation of her faith and her ability to feel empathy towards others. The image of the ladybug tattoo was placed on Ann's body in the same spot as her younger sister's scar following an open-heart surgery.

\section{Tactile Meaning}

Tactile meanings are the meanings involved in bodily sensations of touch, taste, and smell (Kalantzis et al., 2016). We enact meaning through sequences of actions that rely on these bodily sensations about various objects and things. In the representation of favorite literacy practice, several pre-service teachers reflected on how their bodily sensations of touching and tasting connected to various forms of reading and writing or storytelling. Rita's photograph on family literacy included a visual of her two bare feet standing in Kentucky red clay. According to Rita, taking pictures of their feet became a family tradition in which they "take a picture of their feet together, in the sand, in a creek" anywhere they travel "to tell stories about themselves and the places they went to and saw." Rita also reflected on how the positioning of the foot is important, as the feet need to be covered and be in touch with the sand or the water. Taking a picture of the feet represented her family's background as farmers and their resilience in the face of many challenges in life: they always stayed "down to earth" and were firm in their belief of hard work. This family tradition inspired the school writing project of her son who wrote about his toes under the caption favorite body part. Rita described the hard work and storytelling that she inherited from her family and community as part of her funds of knowledge encapsulated by the image of her feet.

\section{Authentic Writing as Meaning-making}

Alina's literacy Self is connected to her life experiences as an English language learner. She described how in $3^{\text {rd }}$ grade one authentic writing project changed her perspective about learning and teachers and it contributed to her decision to become a teacher. Besides working closely on language skills-for example, tips on learning vocabulary or providing detailed information on how to 
structure sentences in English-her $3^{\text {rd }}$-grade teacher also allowed her to write about topics that she was interested in. "Instead of a worksheet and out-of-context topics," Alina's teacher allowed her to write about her home country that she still really missed at the time. Her visual was an image of her first self-crafted book, her first extended writing piece in English, which she wrote about her country of origin in Eastern Europe (see Figure 2). This experience not only taught her that "writing could make someone happy" but also that as a teacher "you could change children's life" and make them feel valued. According to Alina, because of those experiences, the ability to mentor became a part of her funds of knowledge.

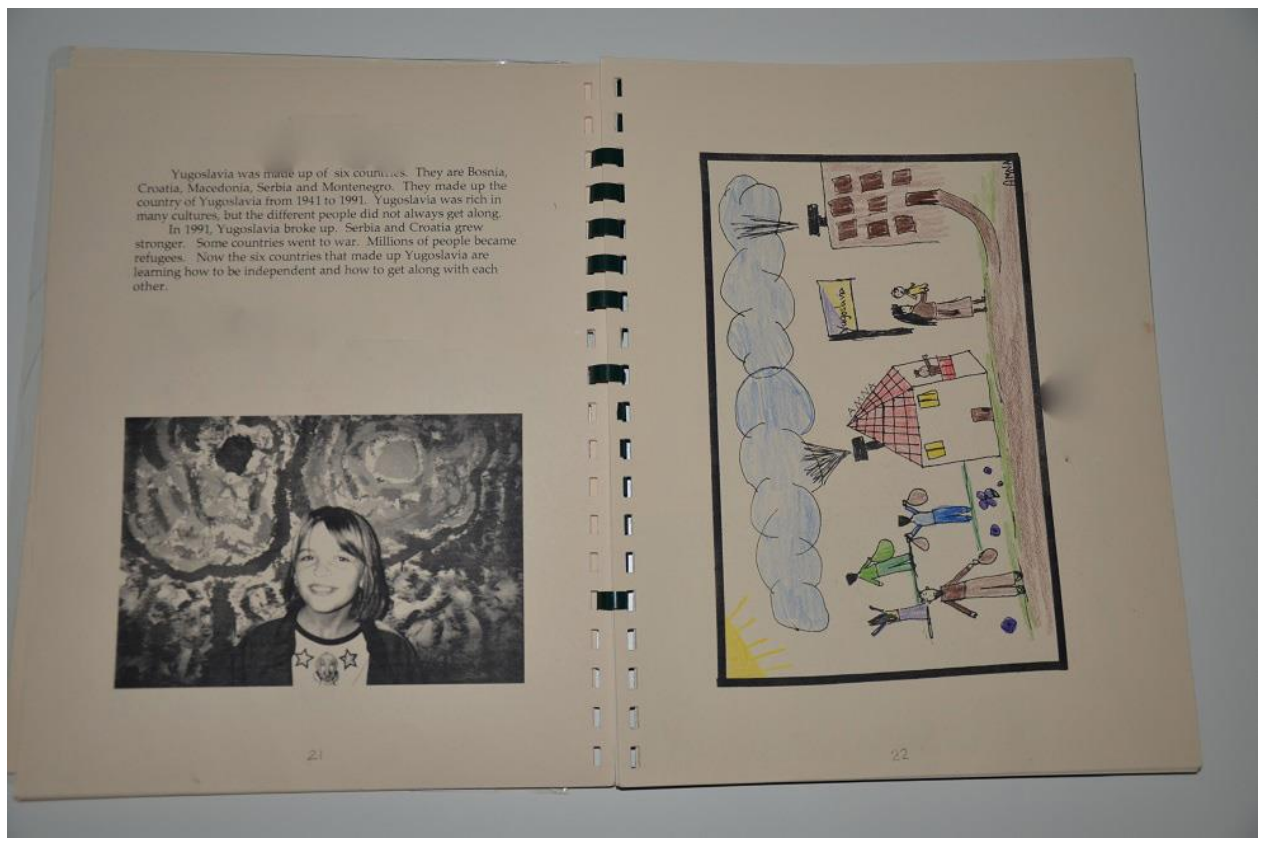

Figure 2. Writing

Similarly, writing became a meaning-making experience for Bee as well, and it connected to the practice of cooking. She described engaging in cooking as a form of everyday literacy, a "true love" that she does with her children. Her photograph (see Figure 3) captures three identical recipe cards with the description of Pecan Pie, Chocolate Cake, and Pumpkin Pie deserts. Beyond creating comfort food for others, baking is also relevant because "collecting recipes and placing it in the family recipe book is a tradition" that the family has continued from generation to generation. An important aspect of this tradition is that the recipes have to be hand-written on the same blue-rimmed index card that the grandmother first used, a responsibility that Bee passed down to her daughter. For Bee, cooking and literacy were closely tied as important aspects of her funds of knowledge. 


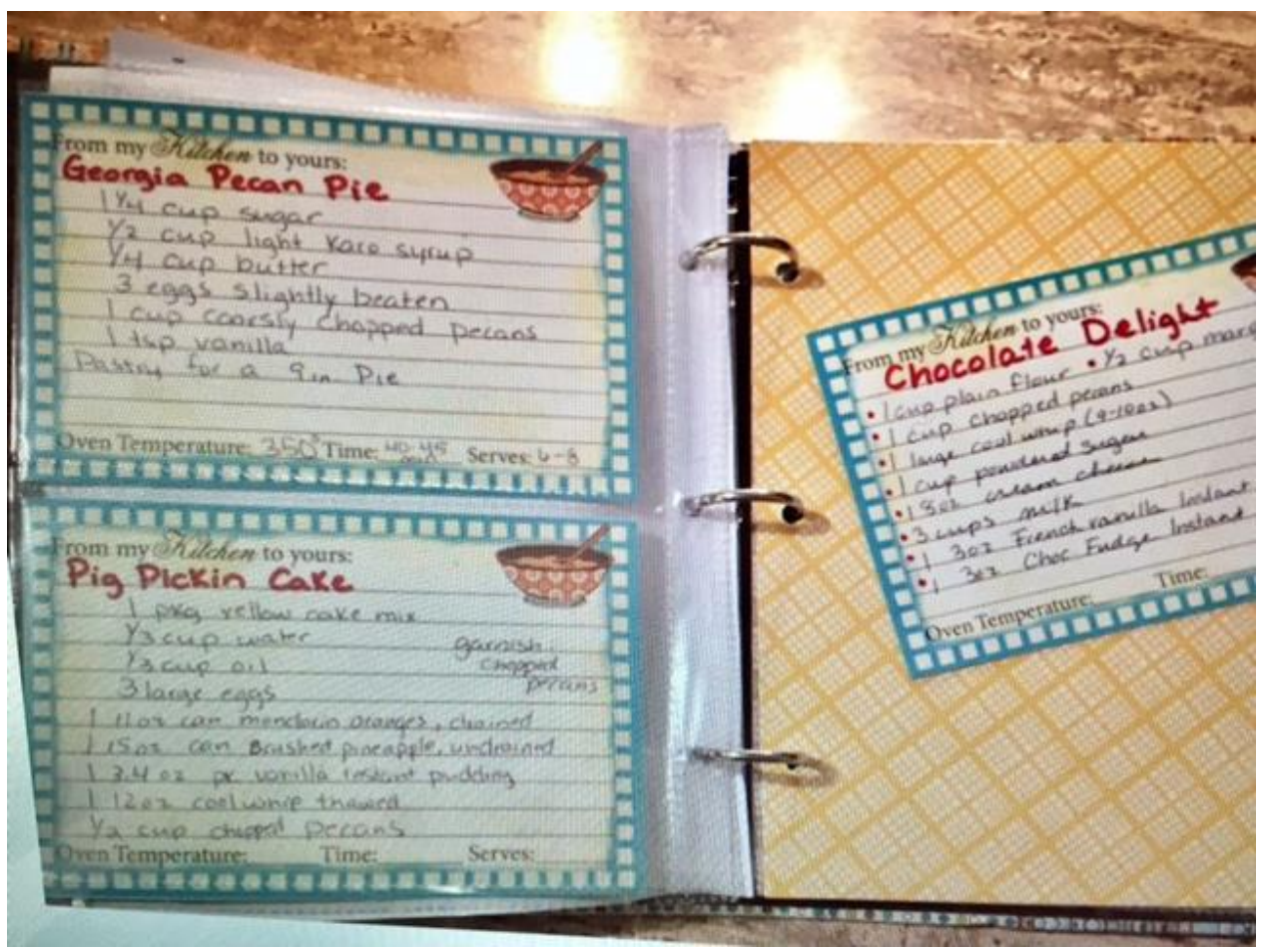

Figure 3. Recipes

\section{Discussion}

In the process of investigating their funds of knowledge, pre-service teachers remixed various elements of their outside world to create meaning and position themselves as part of that world. In this process, they relied on spatial, gestural, and tactile elements, as well as authentic writing, to create a visual representation. Their Cultural Selfie as remix allowed them to connect those representations to their Self in order to comprehend how that Self has been shaped. These Cultural Selfies do not provide definitive answers about the individual; they rather draw attention to the power of stories, visual or other, as instruments of meaning-making and representations of lived experience.

The Cultural Selfie as remix of visual interpretation provided a space for pre-service teachers to view their everyday cultural and literacy practices critically. Specifically, students reflected on how creating these Selfies helped them understand better who they are as members of a family or who they are as teachers, and how culture shapes their interactions and perceptions of the children with whom they are working. Through these Cultural Selfies, pre-service teachers created a map of their own worlds (Bruner, 1986), some aspects of which were difficult to share. Some pre-service teachers shared their discomfort in interacting with somebody who does not speak English and their tendency to stereotype based on social-economic status or race. As they presented their Cultural Selfies and talked about themselves, some of them fell victim to their own preconceived 
notions of cultural stereotypes: e.g., being too "country," having the attitude of the "ghetto," or "of the hillbilly." These "self-characterizations" also became opportunities to reflect on how deeply rooted bias is in language, how that bias may create our reality, and what we can do to use language with more awareness and care towards others or ourselves. In the process of witnessing and structuring their own experiences, visual images helped pre-service teachers "take a close look at cultural systems...learned behavior...cultural underpinnings of own beliefs, attitudes and practices" (Ladson-Billings, 2006, p. 109). Putting a self-portrait together allowed them to recognize their own strengths and biases-and their selfcorrecting practice to be aware.

While there is no assurance that the Cultural Selfie assignment on its own allowed these pre-service teachers to dismantle the stereotypes, it gave them an opportunity to verbalize their own biases and prejudices, and their insecurities and strengths. Additionally, for pre-service teachers who were first-generation immigrants or represented a racial minority, the Cultural Selfie became an empowering way to tell their own stories and to talk back to the stereotyping that they may have faced. By sharing their Selfies and learning about each other's differences and similarities, pre-service teachers engaged in intercultural learning. Hawley and Nieto (2010) argued that "people seldom believe in practices they don't know how to implement" (p. 70). Thus, remixing aimed to provide an opportunity for those students "who feel bored, powerless, disenfranchised, angry" (Schaafsma, 1989, p. 90) to tell their stories, and for those who come from more privileged backgrounds to think about their life experiences in critical ways (VargaDobai, 2015).

\section{Implications}

By capturing various scenes and artifacts of their everyday life, pre-service teachers also explored the pedagogical and methodological tool of funds of knowledge (Moll et al., 1992; Gonzalez et al., 2005). The Cultural Selfie became an artistic representation of their own histories. Hedges (2015) claimed that incorporating funds of knowledge in teaching "assists teacher understanding, action and reflection" (p. 84). Hogg (2011) similarly asserted that the understanding of funds of knowledge "builds teachers' knowledge of their students" (p. 667), and it builds teachers' knowledge of themselves as well. Beyond enabling students to recognize their own membership in cultural and ethnic communities, funds of knowledge effectively connect children's out-of-school knowledge to the curriculum. In instructional settings the use of funds of knowledge goes beyond the well-established use of background or prior knowledge (Razfar \& Rumenapp, 2013), a cognitive approach that seeks out what children already know about a particular topic in the curriculum. The funds of knowledge approach, instead, seeks out what children are interested in and will match the school curriculum to those interests and experiences: a themed unit on cooking may offer valuable lessons on math, science, or literacy. In the context of literacy, Pirbhai-Illich (2010) 
describes a digital literacy project in which the self-selected topics of interest enabled Aboriginal students to share their stories and to engage with research, writing, and editing skills in meaningful ways.

The Cultural Selfie Project served as a remix that fostered the self-discovery of these pre-service teachers as women, educators, and members of culture, as well as users of literacy. My hope is that the pre-service teachers involved in this study will continue to use this self-reflective practice in the future to ask questions about their own practice and to listen to the stories children tell. The funds of knowledge approach creates richer and more effective literacy learning opportunities that connect school with the outside world and confirm the relevance of culture in how we perceive and perform our lives.

\section{References}

Becker, A. (2014). Funds of (difficult) knowledge and the affordances of multimodality: The case of Victor. Journal of Language and Literacy Education, 10(2), 17-33.

Bennett, J. M. (1986). Modes of cross-cultural training: Conceptualizing crosscultural training as education. International Journal of Intercultural Relations, 10, 117-134.

Bennett, M. J. (1996). A developmental approach to training for intercultural sensitivity. International Journal of Intercultural Relations, 19(2), 179-195.

Bruner, J. (1986). Actual minds, possible worlds. Cambridge, MA: Harvard University Press.

Chilton, G. (2013). Altered inquiry: Discovering arts-based research through an altered book. International Journal of Qualitative Methods, 12, 457-477.

Fraser, K. D., \& Sayah, F. (2011). Arts-based methods in health research: A systematic review of the literature. Arts \& Health, 3(2), 110-145.

Gainer, J. S., \& Lapp, D. (2010). Remixing old and new literacies=Motivated students. English Journal, 100(1), 58-64.

Goffman, E. (1959). The presentation of self in everyday life. Garden City, NY: Doubleday.

Gonzalez, N., Moll, L., \& Amanti, C. (2005). Introduction: Theorizing practices. In N. Gonzalez, L. C. Moll, \& C. Amanti (Eds.), Funds of knowledge: Theorizing practices in households, communities and classrooms (pp. 128). Mahwah, NJ: Lawrence Erlbaum.

Harste, J. (2003). What do we mean by literacy now? Voices from the Middle, 10(3), 8-12.

Hawley, W. D., \& Nieto, S. (2010). Another inconvenient truth: Race and ethnicity matter. Closing Opportunity Gaps, 68(3), 66-71. 
Hedges, H. (2015). Sophia's funds of knowledge: Theoretical and pedagogical insights, possibilities and dilemmas. International Journal of Early Years Education, 23(1), 83-96.

Hogg, L. (2011). Funds of knowledge: An investigation of coherence within the literature. Teaching and Teacher Education, 27(3), 666-677.

Kalantzis, M., Cope, B., Chan, E., \& Dalley-Trim, L. (2016). Literacies (2 ${ }^{\text {nd }}$ ed.). Cambridge, United Kingdom: Cambridge University Press.

Katz, J. E., \& Crocker, E. T. (2015). Selfies and photo messaging as visual conversation: Reports from the United States, United Kingdom and China. International Journal of Communication, 9(2015), 1861-1872.

Kiyama, J. M. (2014). Family lessons and funds of knowledge: College-going paths in Mexican American families. Journal of Latinos and Education, 10(1), 2342.

Knobel, M., \& Lankshear, C. (2008). Remix: The art and craft of endless hybridization. Journal of Adolescent and Adult Literacy, 52(1), 22-33.

Koliska, M., \& Roberts, J. (2015). Selfies: Witnessing and participatory journalism with a point of view. International Journal of Communication, 9(2015), 1672-1685.

Kress, G. (1997). Before writing: Rethinking the paths to literacy. London, United Kingdom: Routledge.

Kress, G., \& Van Leeuwen, T. (1996) Reading images: The grammar of visual design. London, United Kingdom: Routledge.

Ladson-Billings, G. (2006). It's not the culture of poverty, it's the poverty of culture: The problem with teacher education. Anthropology and Education Quarterly, 37(2), 104-109.

Leavy, P. (2015). Method meets art. Arts-based research practice. New York, NY: Guilford Press.

Marshall, E., \& Toohey, K. (2010). Representing family: Community funds of knowledge, bilingualism, and multimodality. Harvard Educational Review, 80(2), 221-242.

Meoli, P. (2001). Family Stories Night: Celebrating culture and community. The Reading Teacher, 54(8), 746-747.

Moll, L., Amanti, C., Neff, D., \& Gonzalez, N. (1992). Funds of knowledge for teaching: Using a qualitative approach to connect homes and classrooms. Theory Into Practice, 31(1), 132-141.

Mui, S., \& Anderson, J. (2008). At home with the Johars. Another look at family literacy. The Reading Teacher, 62(3), 234-243.

Nemer, D., \& Freeman, G. (2015). Empowering the marginalized: Rethinking selfies in the slums of Brazil. International Journal of Communication, 9(2015), 1832-1847. 
Nieto, S. (2010). Language, culture, and teaching: Critical perspectives (2nd ed.). New York, NY: Routledge.

Paris, D., \& Alim, S. H. (2017). Culturally sustaining pedagogies: Teaching and learning for justice in a changing world. New York, NY: Teachers College Press.

Pirbhai-Illich, F. (2010). Aboriginal students engaging and struggling with critical multiliteracies. Journal of Adolescent \& Adult Literacy, 54(4), 257-266.

Razfar, A., \& Rumenapp, J. C. (2013). Applying linguistics in the classroom: A sociocultural approach. New York, NY: Routledge.

Riessman, C. K. (2005). Narrative analysis. In N. Kelly, C. Horrocks, K. Milnes, B. Roberts, \& D. Robinson (Eds.), Narrative, memory \& everyday life (pp. 17). Huddersfield, United Kingdom: University of Huddersfield.

Riessman, C. K. (2008). Narrative methods for the human sciences. Thousand Oaks, CA: Sage Publications.

Rizvi, F. (2009). Toward cosmopolitan learning. Discourse: Studies in the Cultural Politics Education, 30(3), 253-268.

Rose, T. (1994). Black noise: Rap music and black culture in contemporary America. Hanover, MA: Wesleyan University Press.

Saltz, J. (2014, January 26). Art at arm's length: A history of the selfie. Vulture. Retrieved from http://www.vulture.com/2014/01/history-of-the-selfie.html

Schaafsma, D. (1989). Research in the classroom: Gilberts's and Dave's stories: Narrative and knowing. The English Journal, 78(7), 89-91.

Street, B. (1997). The implications of the New Literacy Studies for education. English in Education, 31(3), 45-59.

Tiidenberg, K. (2014). Bringing sexy back: Reclaiming the body aesthetic via selfshooting. Cyberpsychology, 8(1), 1-3.

Varga-Dobai, K. (2015). Responding to literature through storytelling, artifacts, and multigenre writing practices: Explorations of cultures and self. Literacy, 49(2), 77-83.

Wajskop, G., \& Peterson, S. S. (2015). Dramatic Play as a meaning-making and story-making activity. Early Childhood Education, 43(1), 17-20.

Wiltse, L. (2014). Not just 'sunny days': Aboriginal students connect out-of-school literacy resources with school literacy practices. Literacy, 49(2), 60-68.

Zipin, L. (2009). Dark funds of knowledge, deep funds of pedagogy: Exploring boundaries between lifeworlds and schools. Discourse: Studies in the Cultural Politics of Education, 30(3), 317-331. 


\section{Author Contact}

Kinga Varga-Dobai: kvargado@ggc.edu

Georgia Gwinnett College, 1000 University Center Ln, Lawrenceville, GA 30043, U.S. A. 